\title{
Ultrasonographic findings of uterine defect after surgical evacuation of abnormal pregnancy
}

\begin{abstract}
Perforation of the uterus usually results from either iatrogenic or, less frequently, spontaneous occurrences. Iatrogenic etiologies include perforations occurring during dilation and curettage, hysteroscopy and insertion of intrauterine contraceptive devices. Spontaneous etiologies include pyometra, gestational trophoblastic disease, placenta accrete and rarely degeneration of a myoma and uterine infarction. Procedure-related uterine perforation is usually considered and diagnosed clinically at the time of injury, hence the relative sparse literature regarding the imaging findings associatedwith uterine perforation. We report an unusual case in which uterine perforation was confirmed by sonography after pregnancy termination at 10 weeks' gestation. We discuss the diagnosis and treatment.
\end{abstract}

Keywords: ultrasound, uterine perforation, abortion
Volume 3 Issue I - 2015

\begin{abstract}
Ahmed Samy El-Agwany, Tamer Mamdouh Abdeldayem, Mervat Ali El-Sersy

Department of Obstetrics and Gynecology, Faculty of Medicine, Alexandria University, Egypt
\end{abstract}

Correspondence: Ahmed S El-Agwany, Department of Obstetrics and Gynecology, Faculty of Medicine, Alexandria University, Alexandria, Egypt, Tel 0020I228254247,

Email Ahmedsamyagwany@gmail.com

Received: October 8, 20I5 | Published: November 02, 2015

\section{Introduction}

Uterine perforation is an uncommon but serious complication of abortion or evacuation of placental parts retained during the puerperium. ${ }^{1,2}$ The most hazardous problem is uterine rupture during a subsequent pregnancy. Reported cases have used ultrasound to diagnose uterine dehiscence or rupture. ${ }^{3,4}$ In this report, we describe a rare case of uterine perforation following curettage, which was diagnosed by Sonography and managed successfully by conservative management.

\section{Case report}

A 29-year-old multiparous woman at 11weeks' gestation was referred to our hospital for termination of pregnancy due to suspected placenta accreta or cesarean scar ectopic by abnormal vasculature around lower uterine segment gestational sac on ultrasound. She had delivered 2 male children by cesarean section. The patient underwent ultrasound due to complain of vaginal bleeding. It revealed lower uterine segment pregnancy with abnormal vasculature in the placenta bed suspicious of placenta accreta or cesarean scar ectopic pregnancy about 10weeks gestation (Figure 1). The decision was done to evacuate the pregnancy vaginally by surgical means. The patient underwent surgical evacuation under ultrasound guidance but severe vaginal bleeding occurred. The procedure was ended and uterovaginal packing was done for $24 \mathrm{hrs}$. The patient was vitally stable. The procedure was performed transabdominal ultrasound examination after $24 \mathrm{hrs}$ that revealed bulky uterus with hematoma inside cavity and there was a defect $(3 \mathrm{~cm} \times 2.0 \mathrm{~cm})$ in the lower anterior uterine wall with no fluid collection in the abdomen (Figures 2-5). The patient was vitally stable with no vaginal bleeding. We removed the vaginal pack intraoperative under general anesthesia, prepared for laparotomy in case of severe bleeding. No bleeding occurred, the patient discharged after 1 week and follow-up after one month revealed normal uterus.

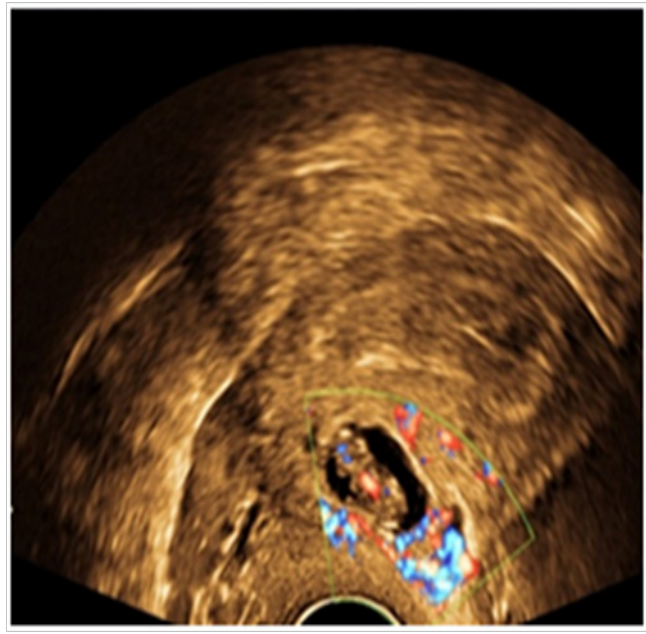

Figure I lower uterine segment with abnormal vasculature in placenta bed suspicious of early placenta accreta or cesarean scar ectopic pregnancy.

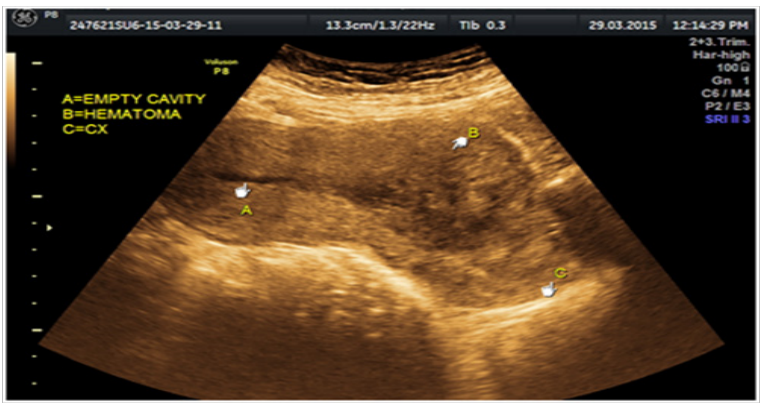

Figure 2 Transabdominal ultrasound revealing hematoma in the lower uterine segment after evacuation. 


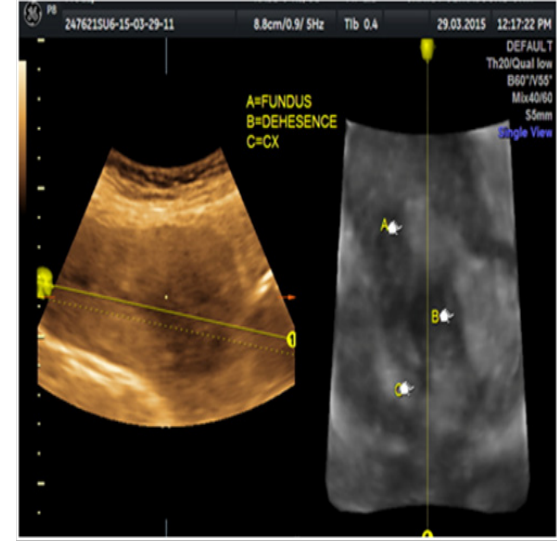

Figure 3 Transabdominal ultrasound revealing defect in the lower anterior wall on $3 \mathrm{D}$ view.

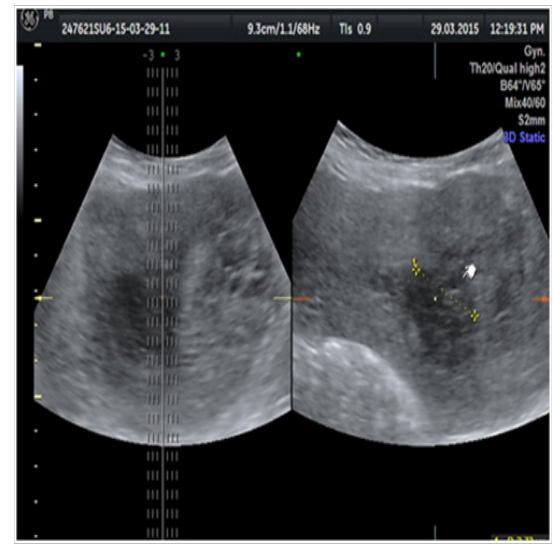

Figure 4 Uterine defect about $3 \mathrm{~cm}$

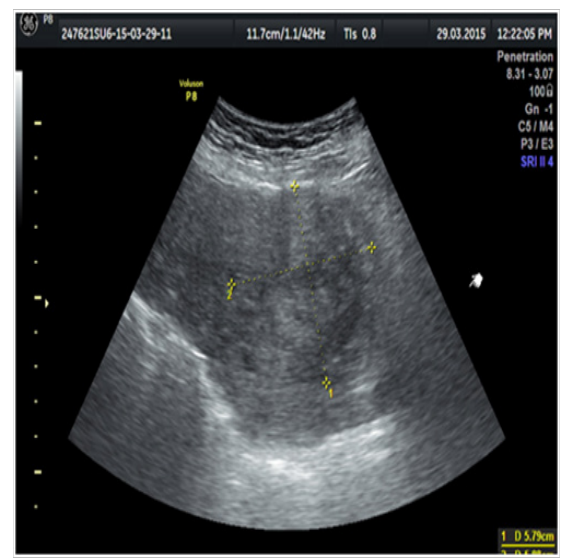

Figure 5 Hematoma intrauterine about $5 \mathrm{~cm}$.

\section{Discussion}

Uterine perforation is a potentially serious complication of abortion. The incidence associated with abortion by suction curettage is around $0.08-0.17 \%{ }^{1,2}$ Perforation of the uterine fundus may be symptom free and in most following curettage may be neither suggested nor detected. Rupture of the uterus in a subsequent pregnancy is the most hazardous problem of uterine perforation that often results when there is scarring. Few cases have been reported in literature of sonographic diagnosis of uterine defect as a complication of curettage. With the aid of sonographic imaging, the diagnosis was suggested based on the visualization of the uterine discontinuity and multiple cystic masses within the myometrium. It should be borne in mind that uterine rupture often occurs late in gestation in those cases with a history of uterine perforation. ${ }^{3-7}$

Routine sonographic follow-up examinations are recommended during pregnancy when there is a history of curettage or intrauterine manipulation. With the aid of sonographic examinations, we successfully identified a uterine defect arising from a uterine perforation. Sonographic depictions of free fluid in the pelvis, loops of bowel within the myometrial wall or endometrial cavity, extra uterine fetal parts, or the intraoperative presence of the curette within the myometrium have confirmed clinically suspected uterine perforation. Increased sonographic resolution and the application of highresolution Sonography have enhanced direct sonographic depiction of uterine perforation and procedure related intramural hematomas. ${ }^{8-11}$

We should be aware of the rising complication of cesarean section of early placenta accreta or cesarean scar ectopic. Ultrasound raises its suspicion by lower sac with abnormal vasculature at the site of cesarean scar. Ultrasound aids in diagnoses of uterine defect in experienced hands. Uerine defects can be managed conservatively without repair and the patient is counseled for risk of rupture in next pregnancy and repeat cesearean section. Abnormal pregnancy in the lower uterine can be managed by hysteroscopic removal, surgical removal or hysterectomy.

\section{Acknowledgements}

None.

\section{Conflict of interest}

The author declares no conflict of interest.

\section{References}

1. Stepan JG, Gelberman RH, Rubin DA, et al. Extra-articular lipoma arborescens of the dorsal aspect of the wrist with invasion of the extensor tendons a case report. JBJS Case Connect. 2013;3(1):e30.

2. Chen LH, Lai SF, Lee WH, et al. Uterine perforation during elective first trimester abortion: a 13-year review. Singapore Med J. 1995;36(1):6367.

3. Lindall G, Flam F. Management of uterine perforations in connection with legal abortions. Acta Obstet Gynecol Scand. 1995;74(5):373-375.

4. Fedorkow DM, Nimrod CA, Taylor PJ. Ruptured uterus in pregnancy: a Canadian hospital's experience. CMAJ. 1987;137(1):27-29.

5. Stanco LM, Schrimmer DB, Paul RH, et al. Emergency peripartum hysterectomy and associated risk factors. AmJ Obstet Gynecol. 1993;168(3 Pt 1):879-883

6. Miller DA, Mullin P, Hou D, et al. Vaginal birth after cesarean delivery in the twin gestation. Am J Obstet Gynecol. 1989;175(1):194-198.

7. Martin JN, Morrison JC, Wiser WL. Vaginal birth after cesarean section: the demise of routine repeat abdominal delivery. Obstet Gynecol Clin North Am. 1988;15(4):719-736.

8. Cheng PJ, Chueh HY, Soong YK (2003) Sonographic diagnosis of a uterine defect in a pregnancy at 6 weeks' gestation with a history of curettage. Ultrasound Obstet Gynecol 21(5):501-503.

9. Shulman SG, Bell CL, Hampf FE. Uterine perforation and small bowel incarceration: sonographic and surgical findings. Emerg Radiol. 2006;13(1):43-45. 
10. Forster BB, Siu CM, Murray JB, et al. Transabdominal and transvaginal sonography of uterine perforation following suction curettage. Can Assoc Radiol J. 1989;40(6):318-319.

11. Skolnick ML, Katz Z, Lancet M. Detection of intramural uterine perforation with real-time ultrasound during curettage. J Clin Ultrasound. 1982;10(7):337-338.
12. Sherer DM, Gorelick C, Gabbur N, et al. Transvaginal sonographic findings of a large intramural uterine hematoma associated with iatrogenic injury sustained at termination of pregnancy. Ultrasound Obstet Gynecol. 2007;30(1):110-113. 